\title{
Occurrence, Temporal Variation and Estrogenic Burden of Five Parabens in Sewage Sludge Collected Across the United States
}

Jing Chen ${ }^{\mathrm{a}}$, Benny F. G. Pycke ${ }^{\mathrm{a}}$, Bruce J. Brownawell ${ }^{\mathrm{b}}$, Chad A. Kinney ${ }^{\mathrm{c}}$, Edward T.

Furlong $^{\mathrm{d}}$, Dana W. Kolpin ${ }^{\mathrm{e}}$, and Rolf U. Halden ${ }^{\mathrm{a}, ~ *}$

${ }^{a}$ Biodesign Center for Environmental Security, Biodesign Institute, School of Sustainable Engineering and the Built Environment and Global Security Initiative, Arizona State University, 781 E. Terrace Mall, Tempe, AZ 85287, United States

${ }^{\mathrm{b}}$ School of Marine and Atmospheric Sciences, Stony Brook University, Stony Brook, NY 11794-5000, United States

${ }^{\mathrm{c}}$ Chemistry Department, Colorado State University-Pueblo, 2200 Bonforte Blvd., Pueblo, CO, 81001, United States

${ }^{\mathrm{d}}$ U.S. Geological Survey, Denver Federal Center, P.O. Box 25585, Denver, CO 80225, United States

${ }^{\mathrm{e}}$ U.S. Geological Survey, 400 S. Clinton Street, Iowa City, IA 52240, United States

*Corresponding author: Rolf U. Halden

Email: rolf.halden@asu.edu

Tel.: (480) 727-0893

Mail: 781 E. Terrace Mall; Tempe, AZ 85287-5904 


\begin{abstract}
Five parabens used as preservatives in pharmaceuticals and personal care products (PPCPs) were measured in sewage sludges collected at 14 U.S. wastewater treatment plants (WWTPs) located in nine states. Detected concentration ranges (ng/g, dry weight) and frequencies were as follows: methyl paraben (15.9 to $203.0 ; 100 \%)$, propyl paraben $(0.5$ to $7.7 ; 100 \%)$, ethyl paraben $(<0.6$ to $2.6 ; 63 \%)$, butyl paraben $(<0.4$ to $4.3 ; 42 \%)$ and benzyl paraben $(<0.4$ to $3.3 ; 26 \%)$. The estrogenicity inherent to the sum of parabens detected in sewage sludge (ranging from 10.1 to $500.1 \mathrm{pg} / \mathrm{kg} 17 \beta$ estradiol equivalents) was insignificant when compared to the $10^{6}$-times higher value calculated for natural estrogens reported in the literature to occur in sewage sludge. Temporal monitoring at one WWTP provided insights into temporal and seasonal variations in paraben concentrations. This is the first report on the occurrence of five parabens in sewage sludges from across the U.S., and internationally, the first on temporal variations of paraben levels in sewage sludge. Study results will help to inform the risk assessment of sewage sludge destined for land application (biosolids).
\end{abstract}

KEYWORDS: Paraben, wastewater treatment plants (WWTPs), estrogenic potential, sludge 


\section{Introduction}

Parabens are a group of compounds that have been extensively used as preservatives in pharmaceutical and personal care products (PPCPs), food, beverages, and industrial products, due to their broad spectrum of antimicrobial activity, good stability over a wide $\mathrm{pH}$ range, and moderate solubility [1]. Recently there has been an increase in the concern over the potential risks of parabens on human and animal health [2] . Parabens are considered to represent a group of emerging endocrine disruptors that cause immune dysfunctions and affect human reproductive outcomes [3-6]. Potential links have been suggested between parabens and breast cancer etiology [7-9]. Furthermore, studies have shown parabens to be toxic to aquatic organisms, such as algae, fish and invertebrate [1013]. With the continuing debate and ongoing study on the safety of parabens, monitoring of parabens in the environment is important for effective assessment and management of ecological risks.

Widespread use of parabens has led to their ubiquitous presence in various environmental matrices, including wastewater, surface water, soil, sediments, sewage sludge and indoor dust [14-19] as well as biological matrices including human urine [20], serum, cord blood [21], breast tissues [22], placenta [23] and amniotic fluid [24]. The most commonly used parabens in commercial products include methyl paraben (MePB), ethyl paraben (EtPB), propyl paraben (PrPB), butyl paraben (BuPB) and benzyl paraben (BePB). As parabens are mainly used in PPCPs, they are continuously released into domestic and industrial wastewater and conveyed through the sewer system to wastewater treatment plants (WWTPs) [25]. Although over $90 \%$ of parabens can be effectively removed during conventional wastewater treatment in which biodegradation plays a significant role, $\mathrm{ng} / \mathrm{L}$ 
levels of parabens are known to remain detectable in treated wastewater [1]. One study reported the total concentration of six parabens including MePB, EtPB, PrPB, BuPB, $\mathrm{BePB}$ and HePB (heptyl paraben) to range from 1.08 to $7.93 \mathrm{ng} / \mathrm{L}$ in the final effluent from two WWTPs in Albany, NY, representing $1.57-8.03 \%$ of the mass loading [26]. During conventional treatment, a fraction of the paraben load can be removed by sorption to sewage sludge. In an advanced WWTP, $91.8 \%$ of initial parabens mass loading was lost mainly due to degradation, while the contribution of sorption and output of primary and excess sludge was about 7.5\% [27]. Since environmental monitoring studies have focused mainly on the aqueous phase (dissolved parabens), only a limited number of studies are available on the presence of parabens in sewage sludge. However, monitoring of parabens in sludge is important for both ecological and human health risk assessments [28]. Treated sewage sludge is being recycled in many countries via application on land, and current sludge disposal practices can lead to contamination of soil, groundwater and surface water in susceptible settings [29]. Thus, the potential effect of such practices on soil and water from paraben contamination needs to be evaluated. There have been few studies worldwide on the occurrence of parabens in sewage sludge [27, 30-32], and only one such study in the U.S. from two WWTPs in the Albany area of New York State [26]. Thus, additional studies are necessary to understand the temporal and spatial variations of parabens in sewage sludge.

The goal of the present study was to address this knowledge gap by determining: 1) the variation of parabens in U.S. sewage sludge from 14 WWTPs located in nine U.S. states; 2) the temporal variations in paraben concentrations in sewage sludge over the course of 
a year at one WWTP; and 3) the estrogenic potency contributed by parabens in sewage sludge relative to levels of co-occurring estrogens.

\section{Methods}

\subsection{Chemicals and Reagents}

Methylparaben (MePB) was purchased from Aldrich (Sigma-Aldrich, St. Louis, MO), and ${ }^{13} C_{6}$-MePB (99\%) were obtained from Cambridge Isotope Laboratories (Andover, MA). Ethylparaben (EtPB), propylparaben (PrPB), butylparaben (BuPB), and benzylparaben (BePB) were purchased from RT Corp (Laramie, WY) (SI, Table S1), and their deuterated standards $\left(d_{5}-\mathrm{EtPB}, d_{4}-\mathrm{PrPB}, d_{4}-\mathrm{BuPB}\right)$ were purchased from $\mathrm{C} / \mathrm{D} / \mathrm{N}$ Isotopes (Quebec, Canada). LC-MS-grade (99\%) methanol, water, and acetic acid were obtained from Fluka and LC-MS-grade acetone was obtained from Sigma-Aldrich (St. Louis, MO). Individual stock solutions of the native and isotopically-labeled compounds were prepared in methanol. The working standards were prepared by serial dilution of stock solutions with methanol prior to use. All stock solutions were stored in glass vials with polytetrafluoroethylene septa at $-20^{\circ} \mathrm{C}$. All glassware was washed with detergent, rinsed with ultrapure water and heated at $550{ }^{\circ} \mathrm{C}$ for 4 hours prior to use.

\subsection{Sewage Sludge Samples}

Sludge samples were collected at 14 sludge-processing facilities located in nine states (Arizona, Indiana, Florida, Maryland, Montana, New York, Texas, Wisconsin, and 
Vermont), with an additional commercially available product (A3) from another plant purchased at a nationwide retail store. We relied on cooperation with WWTPs and U.S. Geological Survey employees to provide the samples studied, which were provided based on condition of nondisclosure of their identity and exact geographic location. Basic information about the WWTP operations is provided in Supporting Information (SI, Table S2). Locations of WWTPs were named from A to N, and each sample was named using the same ID as the plant, except where multiple samples were taken, then numbers were assigned after plant ID.

The facilities sampled in this study treated a broad range of wastewater flows $(<10$ to $>150$ million liters of wastewater per day) and employed a variety of sludge treatment strategies. In the U.S., treated sewage sludge destined for application on land is categorized into Class A and Class B biosolids based on the pathogen reduction criteria described by USEPA (40 CFR Part 503). Class A biosolids contain no detectible levels of pathogens and can be sold or given away in a bag, or to be applied to land, lawn, and home gardens, whereas Class B biosolids are highly treated but may still contain low levels of pathogens [33]. Samples in this study included untreated sludge, Class B biosolids with many of them being subjected to anaerobic digestion, and Class A biosolids prepared using one or two additional treatments (dewatering, extended storage and composting) after digestion. One or two types of sludge from each site were sampled once between March and June of 2009, with additional samples collected $(n=18)$ in plant A between March 25, 2009 and April 7, 2010 for the temporal study. The samples were collected as discrete units, then frozen after sampling, thawed, subsampled, shipped 
to Arizona State University on dry ice in glass jars with polytetrafluoroethylene septa, stored at $-80{ }^{\circ} \mathrm{C}$, and homogenized prior to extraction.

\subsection{Sample Preparation}

Sludge samples were oven dried at $60{ }^{\circ} \mathrm{C}$ for $24 \mathrm{~h}$, and then about $100 \mathrm{mg}$ dried sewage sludge was weighed and transferred into a $15-\mathrm{mL}$ polypropylene conical tube. Ten ng of ${ }^{13} C_{6}$-MePB, $d_{5}$-EtPB, $d_{4}$ - $\mathrm{PrPB}$, and $d_{4}$ - $\mathrm{BuPB}$ were spiked as internal standard. The sludge sample was extracted with a $5-\mathrm{mL}$ solvent mixture of methanol and acetone $(1: 1, \mathrm{v} / \mathrm{v})$ with $10 \mathrm{mM}$ of acetic acid by placement in a sonication bath (Branson 5510) for $60 \mathrm{~min}$. The resultant slurries then were centrifuged at $1500 \mathrm{~g}$ for $5 \mathrm{~min}$ (Eppendorf Centrifuge 5810 R, Hamburg, Germany), and their organic supernatant transferred into clean glass tubes. The extraction step was repeated one more time using $3 \mathrm{~mL}$ of the solvent mixture as above. Extracts originating from the same sample were pooled and concentrated to 0.5 $\mathrm{mL}$ under a gentle stream of nitrogen at $40{ }^{\circ} \mathrm{C}$ using a blow-down station (Thermo Scientific TS-18821). The remaining $0.5 \mathrm{~mL}$ extract was then diluted to $5 \mathrm{~mL}$ with 10 $\mathrm{mM}$ acetic acid in water and further purified by an Oasis MCX cartridge $\left(60 \mathrm{mg} / 3 \mathrm{~cm}^{3}\right.$; Waters, Milford, MA). Each cartridge was conditioned with $5 \mathrm{~mL}$ of methanol followed by $5 \mathrm{~mL}$ of water. The diluted extract was loaded onto the cartridge and rinsed with 12 $\mathrm{mL}$ of $25 \%$ methanol in water followed by $5 \mathrm{~mL}$ of water. The cartridge was dried under vacuum for $30 \mathrm{~min}$ and then the target analytes were eluted with $4 \mathrm{~mL}$ of methanol. The eluate was dried under a gentle flow of nitrogen at $40{ }^{\circ} \mathrm{C}$ and then reconstituted in $1 \mathrm{~mL}$

of methanol. The extract was diluted with 1:1 (v/v) MS grade water prior to injection into 
high performance liquid chromatography-tandem mass spectrometry (HPLC-MS/MS) for analysis.

\subsection{Instrumental Analysis}

A Shimadzu 2100 HPLC (Shimadzu Scientific, Kyoto, Japan) coupled with ABsciex API 4000 triple quadrupole mass spectrometer (Applied Biosystems, Framingham, MA) with electrospray ionization was used for the chemical analysis. The analytes were separated on a Waters $\mathrm{X}$-Bridge $\mathrm{C}_{8}$ column $(4.6 \times 150 \mathrm{~mm}, 3.5 \mu \mathrm{m}$ particle size $)$ preceded by an equivalent guard column using a gradient LC protocol. The injection volume was $10 \mu \mathrm{L}$. Methanol was used as mobile phase A and water as the mobile phase B. The gradient program started at $60 \% \mathrm{~A}$ and then ramped up to $95 \% \mathrm{~A}$ over 4 min, held at $95 \%$ for 3.5 min, followed by dropping back to $60 \%$ A within $1.5 \mathrm{~min}$, and maintained at $60 \%$ A for 2 min. The ESI was operated under negative mode and the source parameters were set as follows: curtain gas $=172 \mathrm{kPa}$, gas $1=483 \mathrm{kPa}$, gas $2=345 \mathrm{kPa}, \mathrm{IS}=-4500 \mathrm{eV}$, source temperature $=500{ }^{\circ} \mathrm{C}$, entrance potential $(\mathrm{EP})=-10 \mathrm{eV}$, and collision activated dissociation $(\mathrm{CAD})$ gas $=83 \mathrm{kPa}$. Analytes and labeled standards were identified using their specific retention time and multiple reaction monitoring transitions as reported earlier (SI, Table S3) [21].

\subsection{Quality Assurance/Quality Control}

All reported concentrations were determined based on a standard curve containing between 5 to 8 data points at concentrations ranging from 0.01 to $10 \mathrm{ng} / \mathrm{mL}$, with 
minimum coefficients of determination $r^{2} \geq 0.99$. Average recoveries for parabens were determined based on spike-recovery experiments (6 replicates). Relative recoveries, calculated by including information from performance of labeled standards from 6 matrix spike samples, ranged between $78 \pm 11 \%$ for MePB to $113 \pm 6 \%$ for BuPB (SI, Table S4). Average absolute recoveries for isotope standards spiked into all samples were between 65 to $72 \%$.

As detection of background levels of parabens is a known issue resulting from the ubiquity of the compounds [21,26], special care has been taken to avoid possible contaminations. Authors avoided using products containing parabens and wore gloves all the time when handling the samples. All extractions were performed along with method blanks (i.e., procedural controls), and a pure methanol/water mixture $(50 / 50, \mathrm{v} / \mathrm{v})$ was injected once per 10 samples as a check for carryover of parabens from sample to sample. No parabens were found present in solvent blanks, but an average of $1.08 \mathrm{ng} / \mathrm{g}$ of MePB and $0.80 \mathrm{ng} / \mathrm{g}$ PrPB were found in four method blanks. Therefore, mean concentrations measured in method blanks were subtracted from measured concentrations found in samples.

Limit of detection (LOD), limit of quantification (LOQ), and method detection limit (MDL) were determined and are provided in supplemental Table S4. MDLs were determined following the U. S. Geological Survey (USGS) [34] and United States Environmental Protection Agency (USEPA) guidelines, and LOD and LOQ were determined according to the USEPA guideline [35]. Method detection limits (MDLs) for parabens in sludges ranged from 0.28 to $0.97 \mathrm{ng} / \mathrm{g}$, which were comparable to other studies analyzing parabens in sewage sludge [30, 36, 37]. 
For the sewage sludge samples from different locations, based on sample mass availabilities, either duplicates or triplicates were prepared for individual sample. Precisions were expressed either by RPD (relative percentage differences) for duplicates or RSD (relative standard deviation) for triplicates. For the 18 time-series samples from the same plant A, six random samples were extracted in duplicate, and the RPDs were calculated using the following equation:

$$
\mathrm{RPD}(\%)=\frac{\left|\mathrm{C}_{\text {sample }}-\mathrm{C}_{\text {duplicate }}\right|}{\frac{\mathrm{C}_{\text {sample }}+C_{\text {duplicate }}}{2}} \times 100
$$

Where $\mathrm{C}_{\text {sample }}$ and $\mathrm{C}_{\text {duplicate }}$ are the concentrations detected in the original sample and in its duplicate, respectively. Precision expressed by averages of RSDs from triplicates and RPDs from duplicates ranged from $11 \%$ to $19 \%$. These method performance parameters were comparable to those from previous work by others [17], who reported a coefficient of variance $<16 \%$ for duplicate analyses.

\subsection{Data Analysis}

LC-MS/MS data were acquired with Analyst 1.5 software (Applied Biosystem, Foster City, CA). The concentrations of parabens in sludges were calculated using the isotopedilution method and were reported as ng/g on dry weight ( $\mathrm{dw}$ ) basis (all concentrations reported hereafter were on dry weight basis). Concentrations were reported when the analyte peak height to background signal had a signal-to-noise ratio of $>3$, the sample peak areas fell within the dynamic range of the calibration, and the calculated concentrations were above MDL. "Non-detects" failing to meet the above requirements were assigned a conservative value of $\mathrm{MDL} / \sqrt{ } 2$ for statistical analysis, allowing for a 
worst-case scenario analysis that is conservative rather than reflective of the best possible estimate [38]. The average contribution of five parabens in sewage sludge was determined by calculating the mean of the contribution (\%) of individual paraben to the total parabens concentrations in all the samples.

Statistical analyses were performed using Microsoft Excel 2007 and R (version 3.2.2). Correlation among the concentration of individual paraben and the total parabens were analyzed using a non-parametric Spearman's rank correlation test, and the correlation coefficients were expressed using Spearman's rho. For comparison of sludge with different treatments, a Shapiro-Wilk test was used to test the normality of data, and a Bartlette test was performed to determine the variance between groups, then a one-way ANOVA was used for the comparison of total parabens' concentrations in sewage sludge with different treatments. A Tukey HSD test was further performed for pair-wise comparison. A one-way ANOVA test was also used to test seasonal variations of paraben concentrations. The significance levels were set at $p<0.05$ and $p<0.01$.

\subsection{Estradiol Equivalency Quotient Calculation}

The Estradiol Equivalency Quotient (EEQ) contributed by parabens in sewage sludge was calculated using equation 2 :

$$
\mathrm{EEQ}_{\mathrm{i}}=\mathrm{EEF}_{\mathrm{i}} \times \mathrm{C}_{\mathrm{i}}
$$

Where $\mathrm{C}_{\mathrm{i}}$ is the measured concentration of an individual paraben in sludge samples (ng/g, $\mathrm{dw})$, and $\mathrm{EEF}_{\mathrm{i}}$ is the estradiol equivalency factor of an individual paraben, defined as the quotient of $\mathrm{EC} 50_{\mathrm{E} 2} / \mathrm{EC} 50_{\text {Compound }}$, namely the ratio between the half-maximal effective 
concentration of $\mathrm{E}_{2}(17 \beta$-estradiol $)$ and the investigated compound. Three sets of EEFs (SI, Table S5) from three previous studies were used to calculate the EEQs, including minimum, maximum and average EEFs. As an additive estrogenic activity of the endocrine disruptors has been proven, $\sum E E Q$, which represented the overall endocrinedisrupting activity of the sample, was obtained by adding up individual EEQs.

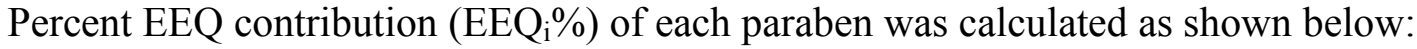

$$
\mathrm{EEQ}_{\mathrm{i}} \%=\frac{\mathrm{EEQ}_{\mathrm{i}}}{\sum \mathrm{EEQ}} \times 100
$$

Average contribution of individual paraben was determined by calculating the mean of EEQ $_{i} \%$ in all samples.

\section{Results and Discussion}

\subsection{Parabens in U.S. Sewage Sludges}

A total of 19 sludge samples from 14 WWTPs were tested for five target parabens (Fig.

1, SI, Table S6), MePB and PrPB were detected in every sample (100\% detection frequency), with a concentration range of $15.9-203.0 \mathrm{ng} / \mathrm{g}$ and $0.5-7.7 \mathrm{ng} / \mathrm{g}$, respectively. EtPB was found in 12 samples $(63 \%)$, ranging from $0.7-2.6 \mathrm{ng} / \mathrm{g}, \mathrm{BuPB}$ was detected in 8 samples (42\%) ranging from $0.6-4.3 \mathrm{ng} / \mathrm{g}$, and BePB was detected in 5 samples $(26 \%)$ with a concentration range of $0.6-3.3 \mathrm{ng} / \mathrm{g}$. The average contribution of individual paraben to total parabens concentration in decreasing order was: $\mathrm{MePB}(89.4 \pm 6.1 \%)>$ $\operatorname{PrPB}(5.7 \pm 3.1 \%)>\operatorname{EtPB}(1.8 \pm 2.5 \%)>\operatorname{BePB}(1.6 \pm 2.7 \%)>\operatorname{BuPB}(1.5 \pm 2.3 \%)$ 
The sum of five parabens' concentration ( $(\mathrm{PBs})$ for each sample is shown in Fig. 2, where sludges were categorized into three groups: untreated sludge $(n=3)$, digested sludge $(n=8)$ and digested sludge with additional treatments $(n=8)$. $\sum$ PBs ranged from 21.2-213.2 ng/g, and the median $\sum \mathrm{PBs}$ concentrations for untreated, digested and digested with additional treatments sludge were $172.1,92.3$ and $45.1 \mathrm{ng} / \mathrm{g}$, respectively. A one-way ANOVA revealed the $\sum$ PBs concentrations for the three groups were statistically different $(p<0.01)$, a Tukey HSD test showed significant differences were found between untreated sludge with treated sludge $(p<0.05)$, and untreated sludge with treated sludge with additional treatments $(p<0.001)$, whereas no significant difference was observed between treated sludge and the ones with additional treatments $(p=0.20)$. Median concentrations of individual paraben in three types of sludge can be found in SI (Table S7).

In general, higher concentrations of parabens were found in untreated sewage sludges compared to those found in treated sludges, indicating that treatment may help decrease parabens in sewage sludge. This difference, however, could also be related to water content, with higher water content in untreated sludge yielding higher parabens concentrations. Different characteristics of the WWTPs including plant location, population, source of release, treatment capacity, sludge production and treatment approaches, also likely contribute to the variability in paraben concentrations. Changes in extractability or other aspects of the sample condition or method performance over the 20-month period could also contribute to the observed variability shown in Fig S2. 


\subsection{Comparison of Paraben Concentrations with Other International Studies}

Data on paraben concentrations in sewage sludge are limited. Most of previous studies generally collected samples from a limited number of WWTPs with limited temporal frequency. Only two previous studies have included multiple WWTPs, one from Spain that analyzed 19 WWTPs [30], and the other investigated 40 WWTPs throughout South Korea [17]. Unlike the current study, most previous research did not specify whether the sludge had been treated or not and what treatment approaches had been applied.

Comparisons of paraben concentrations found in sewage sludge from different locations/countries were listed in Table 1 (also see SI, Fig. S1). Among all previous studies, MePB and PrPB were the most frequently detected and most abundant parabens present in sewage sludge. MePB (15-204 ng/g) and PrPB concentrations $(0.5-7.7 \mathrm{ng} / \mathrm{g})$ found in this study were similar with the ones reported elsewhere (MePB: 4.31-540 ng/g; PrPB: $<0.05-44.1 \mathrm{ng} / \mathrm{g})[17,19,26,27,30-32,37]$. Less frequently detected parabens (e.g. EtPB, BuPB and BePB) from this study were similar to those from South Korea [17]. Overall, the levels of parabens in sludges from United States were comparable to the ones reported elsewhere.

Varying mixtures of parabens are often used to enhance antimicrobial activities [39]; hence, significant positive correlations have been reported among individual parabens concentrations in various environmental monitoring and biomonitoring studies [17, 21]. In this study, a non-parametric Spearman correlation was performed among concentrations of individual parabens and $\sum \mathrm{PBs}$ (Table 2). Similar with the Korea study 
[17], significant positive correlations were observed between MePB and $\operatorname{PrPB}$ concentrations from U.S. sludge. A correlation test also was conducted on reported MePB and PrPB concentrations in sludge from Madrid, Spain [30]. However, the levels of MePB and PrPB in Spain's sewage sludge were not significantly correlated $(r=0.11$, $p=0.65)$. As positive correlations between parabens could be due to the co-occurrence of individual parabens in consumer product formulations [40], the results observed in Spain might indicate that product formulations or consumption practices of parabens in Spain differed from those in the U.S. and Korea.

\subsection{Temporal Variation of Parabens' Concentration in Sludge}

To evaluate temporal changes of paraben concentration in sludge, 18 sludge samples from plant A collected from March 2009 to April 2010 (Fig. 3) were examined.

Concentration ranges for individual parabens were as follows: MePB $(67.2-430.9 \mathrm{ng} / \mathrm{g})$, $\operatorname{PrPB}(1.8-47.7 \mathrm{ng} / \mathrm{g})$, EtPB $(0.4-26.1 \mathrm{ng} / \mathrm{g})$ and BuPB (0.8-9.9 ng/g). Concentration of $\sum$ PBs ranged from 71.5 to $490.1 \mathrm{ng} / \mathrm{g}$, with a median concentration of $227.5 \mathrm{ng} / \mathrm{g}$ (BePB was excluded for this analysis due to its low detection frequency and low concentration). MePB accounted for $80-98 \%$ of $\sum$ PBs, and individual parabens were significantly positively correlated ( $r=0.60-0.78$, SI, Table S8), indicating common source releases for these four parabens throughout the sampling period.

All four parabens share similar temporal trends in that the concentrations were similar between 2009 spring, 2009 summer and the spring of 2010, but increased during fall and winter of 2009. One-way ANOVA tests revealed no significant differences on the concentrations of EtPB, PrPB and BuPB among different seasons, but significant 
differences $(p<0.05)$ were observed for MePB. This observation could be at least partially due to an increase in microbial activity in warmer seasons, resulting in increased biodegradation rates of parabens in wastewater during spring and summer seasons, translating to lower concentrations in sludge. Conversely, decreased microbial activity in colder seasons could translate to higher observed paraben concentrations in fall and winter seasons. Similar behavior has been observed previously in that significantly lower concentrations of PPCPs in sludge were observed in August samples, when compared to the ones from February, May and December with $p$ values of $0.0001,0.0001$, and 0.002 . [19]. To better illustrate the correlations of temperatures and parabens concentration in sewage sludge, daily average temperatures on the sampling dates were compiled (SI, Table S9) and tested against paraben concentration (SI, Table S8). Temperature was significantly negatively correlated with the concentration of $\mathrm{MePB}(r=-0.77, p<0.001)$, $\operatorname{PrPB}(r=-0.77, p<0.001), \mathrm{BuPB}(r=-0.55, p<0.05)$ and the $\sum \mathrm{PB}(r=-0.78, p<$ 0.001). The significant negative correlations observed here were supporting evidence that biodegradation rates were faster in warmer seasons than cooler seasons. However, these variations can also be caused by other factors such as the consumption volume of parabens (i.e. increased use of personal care products during fall and winter), and the operational parameters of WWTPs.

\subsection{Estradiol Equivalency Quotient}

The minimum EEQs in Table 3 indicated lowest EEQs calculated using the lowest concentration of paraben in the samples and the minimum EEF. Conversely, the maximum EEQ were calculated using the maximum EEF and highest concentration 
detected in 19 sludge samples. The lowest EEQ contributed by individual paraben ranged from $0.1 \mathrm{pg} / \mathrm{kg}$ for PrPB to $4.0 \mathrm{pg} / \mathrm{kg}$ for $\mathrm{BePB}$, and the highest ranged from 5.3 for EtPB to $325.9 \mathrm{pg} / \mathrm{kg}$ for BePB. In terms of the individual paraben's contribution to total EEQs, it is unsurprising that although MePB accounted for an average of $89.4 \pm 6.1 \%$ to the total parabens concentrations, it only contributed an average of $39.3 \pm 18.5 \%$ to total EEQs, since the estrogenic potential of parabens increases with the alkyl chain length. In general, as expected, EEQs contributed by the five parabens in U.S. sludges were minimal, with the largest $\sum$ EEQ not exceeding $500.1 \mathrm{pg} / \mathrm{kg}$, and a median $\sum E E Q$ at 88.3 $\mathrm{pg} / \mathrm{kg}$, which was almost $10^{6}$ times lower than the estrogenic activity contributed by natural estrogens present (Estrone $+17 \beta$-Estradiol + Estriol, E1 + E2 + E3) in sewage sludge samples reported at 24.8 to $63.8 \mu \mathrm{g} / \mathrm{kg}[41,42]$.

\subsection{Study Limitations}

The sewage sludge samples in this study were collected in 2009 to 2010, and then kept at $-80^{\circ} \mathrm{C}$ prior to extraction and analysis in 2015 . The widespread use of parabens as longterm preservatives implies that the compounds are expected to be relatively stable under ambient conditions. Aqueous solutions of parabens are reported stable at $\mathrm{pH}$ 3-6 for up to 4 years at room temperature, but have been observed to be subject to hydrolytic attenuation at or above $\mathrm{pH} 8$, with a loss rate of about $10 \%$ or more over the course of 60 days when stored at room temperature [43]. Biosolids collected in the present study were not subjected to lime stabilization, thereby avoiding such degradative high-pH regimes and potentially associated significant analyte loss by hydrolysis. In addition, sludge samples were stored at $-80{ }^{\circ} \mathrm{C}$ upon receipt to avoid potential chemical, physical and 
biological transformation processes. Occurrence of analytes in treated sewage sludge implies that the compounds already had to be refractory enough to withstand aerobic/anaerobic digestion and in some cases additional treatment. For the above stated reasons, notable loss of analytes during sample storage thus was not to be expected. Indeed, repeated analysis of the same samples over a period of 20 months indicated parabens to display marked persistence in archived sludge, with no appreciable losses being evident after long-term storage at $-80{ }^{\circ} \mathrm{C}$ (see Fig. S2 in Supplementary Information). Since there are no reports in the literature on formation of parabens during sample storage and none such phenomena were observed in the experiments conducted here, the data presented in this work should be interpreted as conservative estimates of true concentrations that potentially could have been somewhat higher than the values determined experimentally and reported here.

In this work, potential transformation products of parabens and their hormonal potency was not explored. It is possible that transformation products of parabens were present and that these may increase the total estrogenicity imparted by paraben presence in sewage sludge.

\section{Conclusions}

Parabens were found to be ubiquitously present in the sewage sludge sampled in 14 WWTPs in 9 U.S. states, at a level of $\sum$ PBs $21.2-213.2 \mathrm{ng} / \mathrm{g}$ dry weight. The concentrations of parabens in this study were similar to those observed in previously published studies. The estrogenic activities contributed by parabens in U.S. sludge were 
estimated using EEQ as an indicator, showing minimal estrogenic activities (10.1-500.1 $\mathrm{pg} / \mathrm{kg}, \mathrm{dw}$ ) were contributed by parabens in U.S. sludge compared to that of biogenic estrogens. A temporal study monitoring parabens concentration over 12 months revealed seasonal variations, but generally similar concentrations on an annual scale, indicating a consistent source releasing parabens to WWTPs. This study establishes baseline concentrations for five parabens in sewage sludge from United States, providing important information for future risk assessment and trends of environmental release of parabens.

\section{Acknowledgment}

This project was supported in part by Award Number R01ES020889 from the National Institute of Environmental Health Sciences (NIEHS) and by award LTR 05/01/12 of the Virginia G. Piper Charitable Trust in addition to support from the U.S. Geological Survey Toxic Substances Hydrology Program. The content is solely the responsibility of the authors and does not necessarily represent the official views of the NIEHS or the Virginia G. Piper Charitable Trust. We would like to thank the participating treatment facility operators for providing samples for this study. Any use of trade, firm, or product names is for descriptive purposes only and does not imply endorsement by the authors or the United States Government. 


\section{References}

[1] D. Bledzka, J. Gromadzinska, W. Wasowicz, Parabens. From environmental studies to human health, Environ. Int., 67 (2014) 27-42.

[2] M.G. Soni, I.G. Carabin, G.A. Burdock, Safety assessment of esters of phydroxybenzoic acid (parabens), Food Chem. Toxicol., 43 (2005) 985-1015.

[3] R.S. Tavares, F.C. Martins, P.J. Oliveira, J. Ramalho-Santos, F.P. Peixoto, Parabens in male infertility-is there a mitochondrial connection?, Reprod. Toxicol., 27 (2009) 1-7. [4] E.J. Routledge, J. Parker, J. Odum, J. Ashby, J.P. Sumpter, Some alkyl hydroxy benzoate preservatives (parabens) are estrogenic, Toxicol. Appl. Pharmacol., 153 (1998) 12-19.

[5] J. Boberg, C. Taxvig, S. Christiansen, U. Hass, Possible endocrine disrupting effects of parabens and their metabolites, Reprod. Toxicol., 30 (2010) 301-312.

[6] K.W. Smith, I. Souter, I. Dimitriadis, S. Ehrlich, P.L. Williams, A.M. Calafat, R. Hauser, Urinary paraben concentrations and ovarian aging among women from a fertility center, Environ. Health Perspect., 121 (2013) 1299-1305.

[7] P.D. Darbre, A. Aljarrah, W.R. Miller, N.G. Coldham, M.J. Sauer, G.S. Pope, Concentrations of parabens in human breast tumours, J. Appl. Toxicol., 24 (2004) 5-13. [8] P.D. Darbre, P.W. Harvey, Parabens can enable hallmarks and characteristics of cancer in human breast epithelial cells: a review of the literature with reference to new exposure data and regulatory status, J. Appl. Toxicol., 34 (2014) 925-938. 
[9] A.K. Charles, P.D. Darbre, Combinations of parabens at concentrations measured in human breast tissue can increase proliferation of MCF-7 human breast cancer cells, J. Appl. Toxicol., 33 (2013) 390-398.

[10] J.M. Brausch, G.M. Rand, A review of personal care products in the aquatic environment: environmental concentrations and toxicity, Chemosphere, 82 (2011) 15181532.

[11] M. Terasaki, R. Abe, M. Makino, N. Tatarazako, Chronic toxicity of parabens and their chlorinated by-products in Ceriodaphnia dubia, Environ. Toxicol., 30 (2015) 664673.

[12] H. Yamamoto, I. Tamura, Y. Hirata, J. Kato, K. Kagota, S. Katsuki, A. Yamamoto, Y. Kagami, N. Tatarazako, Aquatic toxicity and ecological risk assessment of seven parabens: Individual and additive approach, Sci. Total Environ., 410-411 (2011) 102-111. [13] T. Madsen, H.B. Boyd, D. Nylén, A.R. Pedersen, G.I. Petersen, F. Simonsen, Environmental and health assessment of substances in household detergents and cosmetic detergent products, Environmental Project, 615 (2001) 221.

[14] X. Fan, C. Kubwabo, P. Rasmussen, H. Jones-Otazo, Simultaneous quantitation of parabens, triclosan, and methyl triclosan in indoor house dust using solid phase extraction and gas chromatography-mass spectrometry, J. Environ. Monit., 12 (2010) 1891-1897. [15] I. Gonzalez-Marino, J.B. Quintana, I. Rodriguez, R. Cela, Evaluation of the occurrence and biodegradation of parabens and halogenated by-products in wastewater by accurate-mass liquid chromatography-quadrupole-time-of-flight-mass spectrometry (LC-QTOF-MS), Water Res, 45 (2011) 6770-6780. 
[16] L. Wang, C. Liao, F. Liu, Q. Wu, Y. Guo, H.B. Moon, H. Nakata, K. Kannan, Occurrence and human exposure of p-hydroxybenzoic acid esters (parabens), bisphenol A diglycidyl ether (BADGE), and their hydrolysis products in indoor dust from the United States and three East Asian countries, Environ. Sci. Technol., 46 (2012) 1158411593.

[17] C. Liao, S. Lee, H.B. Moon, N. Yamashita, K. Kannan, Parabens in sediment and sewage sludge from the United States, Japan, and Korea: spatial distribution and temporal trends, Environ. Sci. Technol., 47 (2013) 10895-10902.

[18] E.M. Hartmann, R. Hickey, T. Hsu, C.M. Betancourt Román, J. Chen, R. Schwager, J. Kline, G.Z. Brown, R.U. Halden, C. Huttenhower, J.L. Green, Antimicrobial chemicals are associated with elevated antibiotic resistance genes in the indoor dust microbiome, Environ. Sci. Technol., 50 (2016) 9807-9815.

[19] Q. Sun, M. Li, C. Ma, X. Chen, X. Xie, C.P. Yu, Seasonal and spatial variations of PPCP occurrence, removal and mass loading in three wastewater treatment plants located in different urbanization areas in Xiamen, China, Environ. Pollut., 208 (2016) 371-381. [20] A.M. Calafat, X. Ye, L.Y. Wong, A.M. Bishop, L.L. Needham, Urinary concentrations of four parabens in the U.S. population: NHANES 2005-2006, Environ. Health Perspect., 118 (2010) 679-685.

[21] B.F. Pycke, L.A. Geer, M. Dalloul, O. Abulafia, R.U. Halden, Maternal and fetal exposure to parabens in a multiethnic urban U.S. population, Environ. Int., 84 (2015) 193-200. 
[22] G. Shanmugam, B.R. Ramaswamy, V. Radhakrishnan, H. Tao, GC-MS method for the determination of paraben preservatives in the human breast cancerous tissue, Microchem. J., 96 (2010) 391-396.

[23] I. Jimenez-Diaz, F. Vela-Soria, A. Zafra-Gomez, A. Navalon, O. Ballesteros, N. Navea, M.F. Fernandez, N. Olea, J.L. Vilchez, A new liquid chromatography-tandem mass spectrometry method for determination of parabens in human placental tissue samples, Talanta, 84 (2011) 702-709.

[24] C. Philippat, M.S. Wolff, A.M. Calafat, X. Ye, R. Bausell, M. Meadows, J. Stone, R. Slama, S.M. Engel, Prenatal exposure to environmental phenols: concentrations in amniotic fluid and variability in urinary concentrations during pregnancy, Environ. Health Perspect., 121 (2013) 1225-1231.

[25] C. Haman, X. Dauchy, C. Rosin, J.F. Munoz, Occurrence, fate and behavior of parabens in aquatic environments: a review, Water Res, 68 (2015) 1-11.

[26] W. Wang, K. Kannan, Fate of parabens and their metabolites in two wastewater treatment plants in New York State, United States, Environ. Sci. Technol., 50 (2016) 1174-1181.

[27] W. Li, Y. Shi, L. Gao, J. Liu, Y. Cai, Occurrence, fate and risk assessment of parabens and their chlorinated derivatives in an advanced wastewater treatment plant, J. Hazard. Mater., 300 (2015) 29-38.

[28] A.K. Venkatesan, R.U. Halden, Wastewater treatment plants as chemical observatories to forecast ecological and human health risks of manmade chemicals, Sci. Rep., 4 (2014) 3731. 
[29] A.K. Venkatesan, R.U. Halden, National inventory of perfluoroalkyl substances in archived U.S. biosolids from the 2001 EPA National Sewage Sludge Survey, J. Hazard. Mater., 252-253 (2013) 413-418.

[30] B. Albero, R.A. Perez, C. Sanchez-Brunete, J.L. Tadeo, Occurrence and analysis of parabens in municipal sewage sludge from wastewater treatment plants in Madrid (Spain), J. Hazard. Mater., 239-240 (2012) 48-55.

[31] L. Viglino, M. Prevost, S. Sauve, High throughput analysis of solid-bound endocrine disruptors by LDTD-APCI-MS/MS, J. Environ. Monit., 13 (2011) 583-590. [32] Y. Yu, Q. Huang, J. Cui, K. Zhang, C. Tang, X. Peng, Determination of pharmaceuticals, steroid hormones, and endocrine-disrupting personal care products in sewage sludge by ultra-high-performance liquid chromatography-tandem mass spectrometry, Anal. Bioanal. Chem., 399 (2011) 891-902.

[33] J. Walker, L. Knight, L. Stein, Plain english guide to the EPA part 503 biosolids rule, in: Plain english guide to the EPA part 503 biosolids rule, EPA, 1994. [34] C.J.O. Childress, W.T. Foreman, B.F. Connor, T.J. Maloney, New reporting procedures based on long-term method detection levels and some considerations for interpretations of water-quality data provided by the U.S. Geological Survey National Water Quality Laboratory, U.S. Dept. of the Interior, U.S. Geological Survey; Information Services Open-File Report 99-193; Information Services [distributor], 1999. [35] U. EPA., Appendix B, Part 136-Definition and Procedure for the Determination of the Method Detection Limit-Revision 1.11, Fed. Regist., 136 (1984) 317-321. [36] A. Nieto, F. Borrull, E. Pocurull, R.M. Marce, Determination of natural and synthetic estrogens and their conjugates in sewage sludge by pressurized liquid extraction 
and liquid chromatography-tandem mass spectrometry, J. Chromatogr. A, 1213 (2008) 224-230.

[37] A. Nieto, F. Borrull, R.M. Marce, E. Pocurull, Determination of personal care products in sewage sludge by pressurized liquid extraction and ultra high performance liquid chromatography-tandem mass spectrometry, J. Chromatogr. A, 1216 (2009) 56195625.

[38] R.W. Hornung, L.D. Reed, Estimation of average concentration in the presence of nondetectable values, Appl. Occup. Environ. Hyg., 5 (1990) 46-51.

[39] A.M. Peck, Analytical methods for the determination of persistent ingredients of personal care products in environmental matrices, Anal. Bioanal. Chem., 386 (2006) 907939.

[40] Y. Guo, K. Kannan, A survey of phthalates and parabens in personal care products from the United States and its implications for human exposure, Environ. Sci. Technol., 47 (2013) 14442-14449.

[41] E.J. Marti, J.R. Batista, Impact of secondary treatment types and sludge handling processes on estrogen concentration in wastewater sludge, Sci. Total Environ., 470-471 (2014) 1056-1067.

[42] T. Vega-Morales, Z. Sosa-Ferrera, J.J. Santana-Rodriguez, Evaluation of the presence of endocrine-disrupting compounds in dissolved and solid wastewater treatment plant samples of Gran Canaria Island (Spain), BioMed research international, 2013 (2013) 790570 . 
[43] M.G. Soni, S.L. Taylor, N.A. Greenberg, G.A. Burdock, Evaluation of the health aspects of methyl paraben: a review of the published literature, Food Chem. Toxicol., 40 (2002) 1335-1373. 
Fig. 1. Box-and-whisker plot of paraben concentrations in 19 sewage sludge samples from 14 WWTPs located in 9 U.S. states. Numbers in parentheses indicates the number of samples yielding detectable concentrations. Bottom columns represent the compoundspecific method detection limits (MDLs) with the exact value shown inside the column

Fig. 2. Total concentration of five parabens in untreated sludge (orange bar), digested sludge (blue bar), and digested sludge with additional treatment (green bar) from 14 different WWTPs across the U.S. Error bars indicate the sum of standard deviation for each paraben. Median $\Sigma$ PBs concentration for each category of sludges was shown on top right, and the median concentrations were $172.1,92.3$ and $45.1 \mathrm{ng} / \mathrm{g}$ for untreated, digested and digested sludge with additional treatment, respectively.

Fig. 3. Temporal variation of parabens in sewage sludge $(n=18)$ from one WWTP collected during 2009-2010. Panel (A) shows the concentration of MePB and panel (B) includes concentrations for EtPB, PrPB, and BuPB. Error bars indicate minimum and maximum concentration from duplicate extractions. The plant is located in the southwestern U.S. in a humid, subtropical climate. 


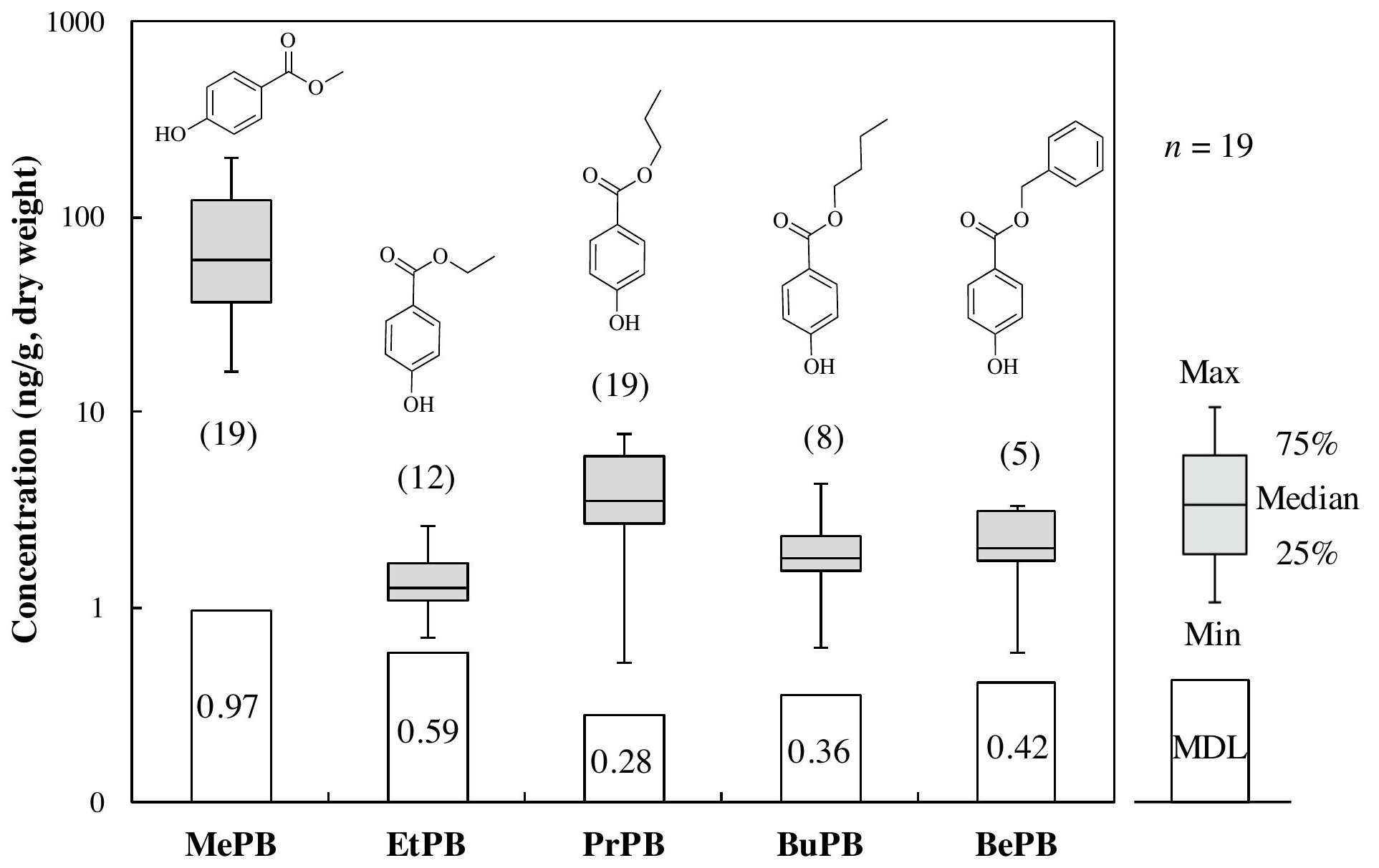




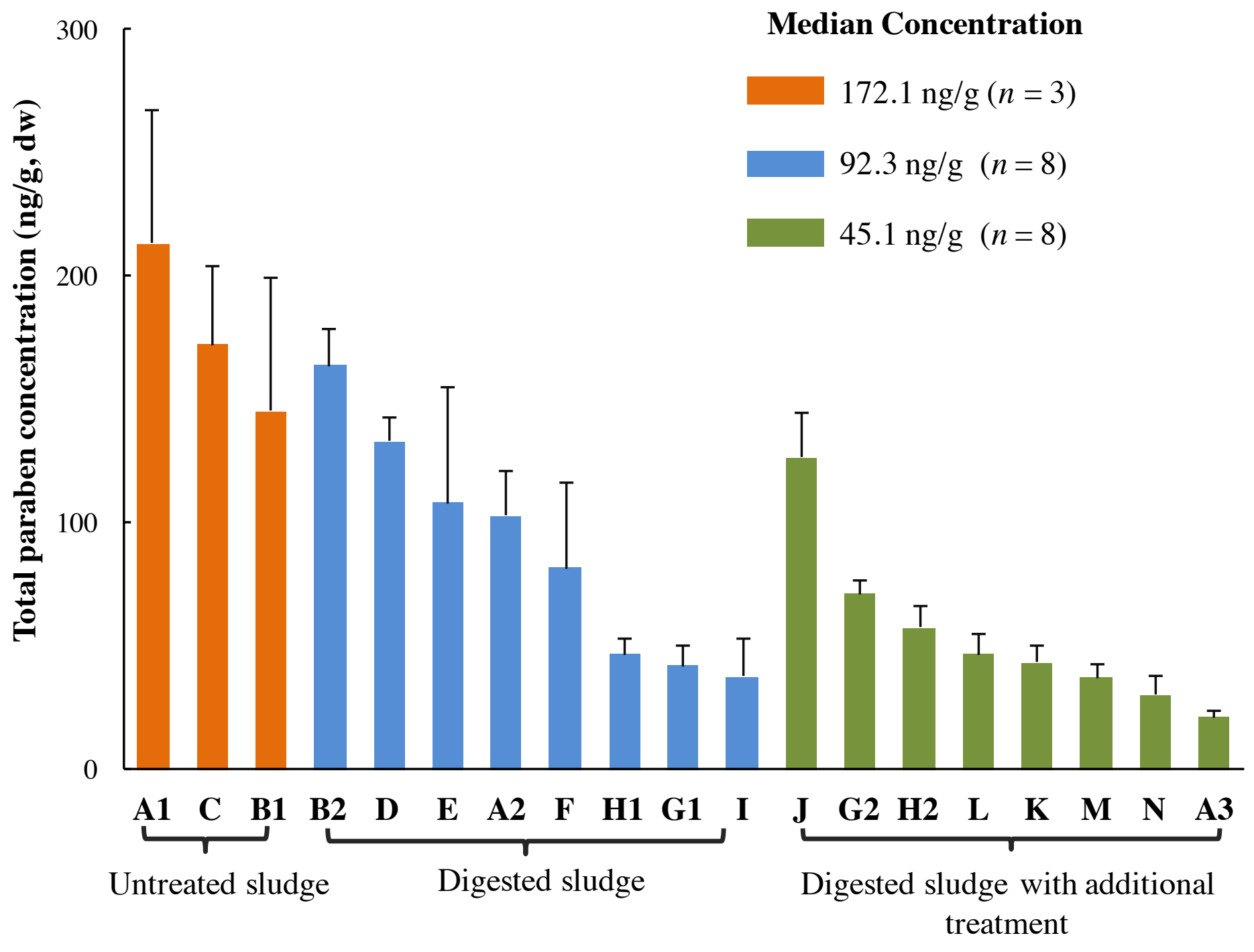




\section{Graphic Abstract}

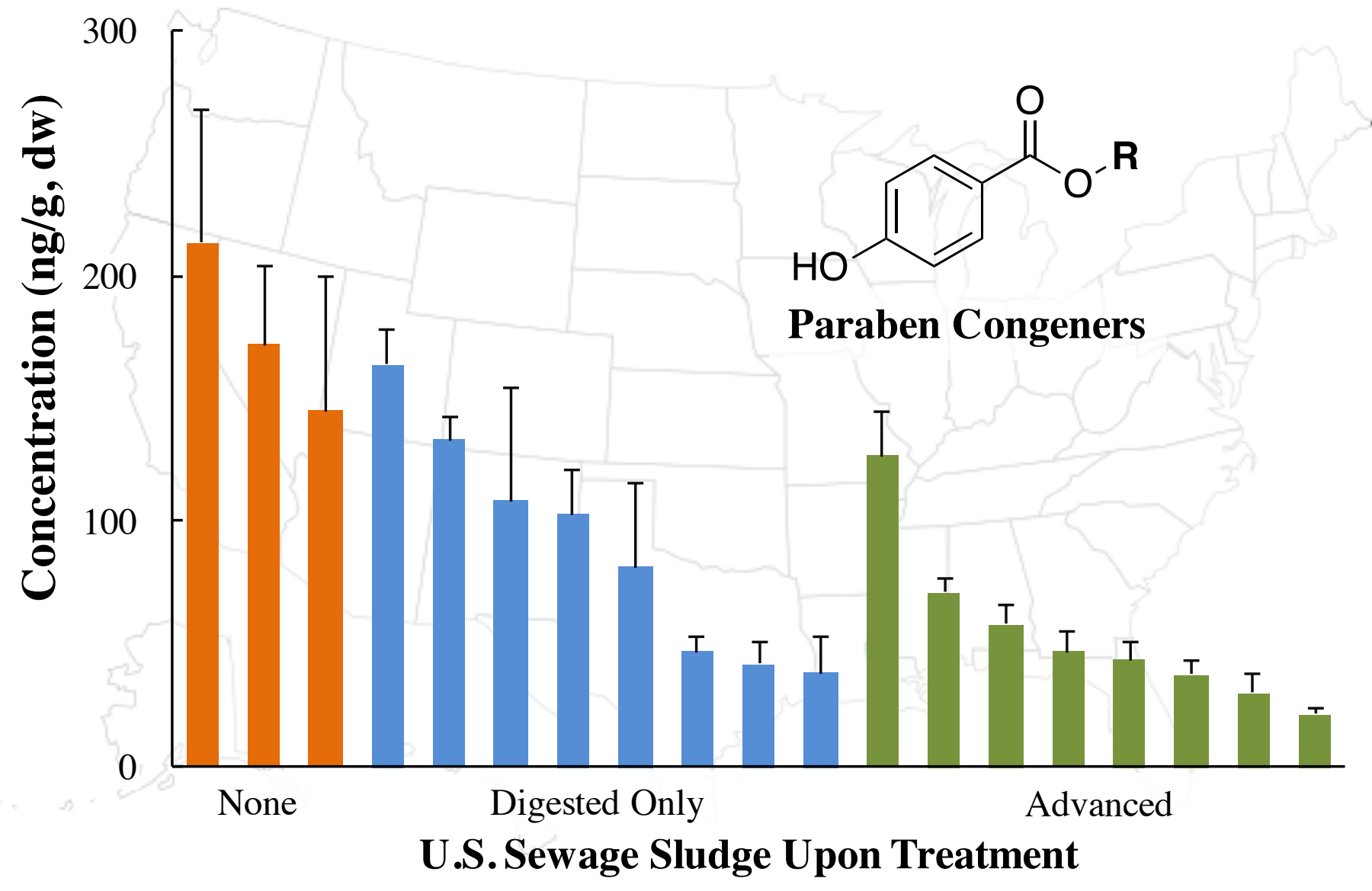


Table 1. Comparison of paraben concentrations in sewage sludge from this study with those from previous research.

\begin{tabular}{|c|c|c|c|c|c|c|c|c|}
\hline \multirow{2}{*}{ Location } & \multirow{2}{*}{ WWTP (\#) } & \multirow{2}{*}{ Sludge Type } & \multicolumn{5}{|c|}{ Concentration (ng/g, dw) } & \multirow{2}{*}{-Reference } \\
\hline & & & $\mathrm{MePB}$ & EtPB & $\operatorname{PrPB}$ & $\mathrm{BuPB}$ & $\mathrm{BePB}$ & \\
\hline Quebec, Canada & 2 & NA & $72-91$ & $<6.4^{\mathrm{a}}$ & $<2.8-8$ & $<2.9$ & $<2.1$ & {$[31]$} \\
\hline Guangzhou, China & 1 & Untreated \& Treated & $5.7-53.5$ & $<0.6$ & $3.6-17.8$ & $<0.3$ & 1 & {$[32]$} \\
\hline Beijing, China & 1 & Untreated & $274-517$ & $1.14-6.80$ & $13.0-29.9$ & $0.62-4.57$ & $<0.4$ & {$[27]$} \\
\hline Xiamen, China & 3 & NA & $8.2-48.1$ & 1 & $<0.1-6.0$ & 1 & $<0.1$ & [19] \\
\hline South Korea & 40 & NA & $4.31-540$ & $<0.1-2.12$ & $<0.05-32.5$ & $<0.05-1.36$ & $<0.1-2.89$ & {$[17]$} \\
\hline Tarragona, Spain & 1 & NA & $46-202$ & $<1.75$ & $6-10$ & 1 & $<3-5$ & {$[37]$} \\
\hline Madrid, Spain & 19 & Treated & $5.1-26.2$ & $<1.1$ & $5.6-44.1$ & $<1.2$ & $<1.0$ & {$[30]$} \\
\hline Albany, U. S. & 2 & Untreated & $24.3-87.4$ & $1.6-12$ & $0.36-4.64$ & $0.36-19.0$ & $<0.01$ & {$[26]$} \\
\hline U. S. & 14 & Untreated \& Treated & $15.9-204.0$ & $<0.6-2.6$ & $0.5-7.7$ & $<0.4-4.3$ & $<0.4-3.3$ & This study \\
\hline
\end{tabular}

“\#”: Number of WWTPs tested in the study; " Non-detects were expressed as " $<$ MDL";

NA: not available; "’" analytes not included in the study 
Table 2. Spearman correlation matrix determined for concentrations of individual and total parabens detected in U.S. sewage sludge $(n=19)$ in this study.

\begin{tabular}{ccccc}
\hline Spearman's rho & MePB & EtPB & PrPB & BuPB \\
\hline EtPB & 0.28 & & \\
PrPB & $0.65^{* *}$ & 0.35 & 0.13 \\
BuPB & 0.29 & 0.33 & & \\
& & & $0.33 * *$ \\
\hline
\end{tabular}

* Correlation is significant at the 0.05 level (2-tailed)

** Correlation is significant at the 0.01 level (2-tailed)

BePB was not included due to its low detection frequency 
Table 3. Calculated Estradiol Equivalency Quotient (EEQ) values of five parabens detected in U.S. sewage sludge samples collected in 2009/2010 $(n=19)$.

\begin{tabular}{ccccccc}
\hline EEQ (pg/kg, dw) & MePB & EtPB & PrPB & BuPB & BePB & EEQPBs \\
\hline Minimum $^{\text {a }}$ & 2.0 & 0.3 & 0.1 & 2.0 & 4.0 & 10.1 \\
Maximum $^{\text {b }}$ & 146.1 & 5.3 & 61.3 & 42.9 & 325.9 & 500.1 \\
Average $^{\text {c }}$ & 36.5 & 1.7 & 14.8 & 9.4 & 34.8 & 97.2 \\
Median $^{\text {d }}$ & 27.4 & 1.4 & 12.3 & 2.3 & 13.1 & 88.3 \\
\hline Contribution (\%) $^{\text {e }}$ & 39.3 & 1.9 & 17.3 & 10.5 & 31.0 & \\
\hline
\end{tabular}

${ }^{a}$ Calculated using the minimum estradiol equivalency factor (EEF) from three studies

${ }^{\mathrm{b}}$ Calculated using the maximum EEF from three studies

${ }^{c}$ The average EEQ for 19 sludge samples calculated using the average EEF from three studies

${ }^{\mathrm{d}}$ The median EEQ for 19 sludge samples calculated using the average EEF

${ }^{\mathrm{e}}$ Mean of the contribution of each individual paraben to the total EEQ in 19 samples 